\title{
A Demanda por Vinho no Brasil: elasticidades no consumo das famílias e determinantes da importação ${ }^{1}$
}

\author{
Alexandre Nunes Almeida ${ }^{2}$, Cassiano Bragagnolo ${ }^{3} \mathrm{e}$
} André Luis Squarize Chagas ${ }^{4}$

Resumo: O objetivo deste trabalho é analisar o mercado brasileiro de vinho e suas recentes mudanças do lado da demanda. Uma das hipóteses que norteia esse trabalho é que o aumento na renda familiar em termos reais e a valorização do Real frente ao dólar, ocorrida mais fortemente entre anos de 2002 e 2011, contribuíram para uma mudança no perfil de consumo das principais bebidas alcoólicas no País. Através da estimação de um Almost ideal Demand System (AIDS), constatou-se que a demanda por vinho se mostra menos elástica no preço do que a cerveja, mas não do que outras bebidas alcoólicas; no entanto, mudanças na renda têm praticamente o mesmo impacto sobre o consumo de vinho e cervejas, mas menos em outras bebidas. Do lado da demanda por vinhos importados no mercado doméstico, através de um Vetor Autorregressivo estrutural (VAR), constatou-se que a maior parte da variância da quantidade do produto importado é explicada pela renda e pelo preço do produto, enquanto o câmbio apresentou menor poder explicativo. Apesar disso, parcela significativa da variância da quantidade não pode ser explicada pelas três variáveis.

Palavras-chaves: Mercado de vinho; Renda; Consumo; Demanda; Taxa de câmbio.

Abstract: The aim of this study is to analyze the Brazilian market of wine and its recent changes on the demand. One of the hypotheses that guides this work is that the recent increase in household income in real terms and the appreciation of Real against dollar quotes, that happened between 2002 until 2011, have contributed to a shift in the consumption profile of main alcoholic beverages in Brazil. To corroborate these hypotheses,

1. Data de submissão: 2 de julho de 2015. Data de aceite: 28 de julho de 2015.

2. Departamento de Economia, Administração e Sociologia da Escola Superior de Agricultura "Luiz de Queiroz" da Universidade de São Paulo - USP. Piracicaba, São Paulo, Brasil. E-mail: alex.almeida@usp.br

3. Departamento de Economia da Universidade Federal de São Carlos - UFSCar - campus Sorocaba. Sorocaba, São Paulo, Brasil. E-mail: cassiano@ufscar.br

4. Faculdade de Economia, Administração e Contabilidade - FEA - da Universidade de São Paulo USP. São Paulo, São Paulo, Brasil. E-mail: achagas@usp.br 
AIDS and VAR Models were estimated. It was observed that the demand for wine is less price elastic than beer but not compared to other alcoholic beverages. Changes in income appear to have almost the same impact on wine and beer consumption than other drinks, less elastic. Regarding the supply of imported wines in the domestic market, the Structural Vector Autoregressive (VAR) showed the variance of the amount of the imported wine could be explained, in part, by income and the price of the product, while exchange rate presented less importance. Moreover, part of the quantity variance cannot be explained by these variables.

Key-words: Wine market; Income; Consumption; Demand; Exchange rate.

DOI - http://dx.doi.org/10.1590/1234-56781806-9479005303004 Classificação JEL: D12, Q11, C30, C22.

\section{Introdução}

O consumo de vinho no Brasil tem apresentado crescimento acentuado nas duas últimas décadas. A maior parte deste crescimento no consumo, entretanto, se baseia em vinhos provenientes de outros países. Dados da Secretaria de Comércio Internacional (Secex) do Ministério do Desenvolvimento, Indústria e Comércio (MDIC), para o período compreendido entre 1995 e 2014, mostram que a importação brasileira de vinhos estrangeiros apresentou taxa de crescimento de 11,2\% ao ano. Em 1995, um ano após o início do Plano Real, os gastos com a importação de vinho eram de 39,6 milhões de dólares e, em 2014, cresceram para 309,4 milhões de dólares, o que representava aproximadamente 120 milhões de garrafas por ano.

$\mathrm{O}$ período recente também marcou $\mathrm{O}$ aumento da produção de vinho no Brasil. A principal região produtora, a Serra Gaúcha tem apresentado vendas crescentes, tanto no mercado doméstico quanto internacional. O número de vinícolas no Rio Grande do Sul cresceu de 439, em 2001, para 738 em 2009 (NIEROP, 2011). O Instituto Brasileiro do Vinho (Ibravin) tem feito projeções que apontam para uma expansão ainda maior para os próximos anos, tanto no que tange ao mercado doméstico quanto ao internacional. A maioria das vinícolas da região é composta por pequenas empresas familiares. Porém, uma quantidade muito pequena de vinícolas é formada por empresas relativamente grandes, como Miolo, Salton, Aurora, Casa Valduga e Peterlongo. Estas grandes vinícolas têm a maior parcela de mercado.

Não obstante, o País vive um momento econômico bastante distinto daquele de décadas passadas. Com a implementação do Plano Real em 1994 e a estabilidade da moeda somadas ao ganho de poder aquisitivo da população a partir de 2002, novas gerações de indivíduos experimentaram um quadro econômico até então inédito no País. Esse aspecto foi e é de importância relevante na vida das famílias, dado que o controle sustentado da inflação permite ao chefe de família planejar por prazos maiores seu orçamento doméstico em função da renda obtida, melhorando o bem-estar através do consumo de produtos nunca antes consumidos.

Assim, tanto os dados relacionados ao aumento da demanda, seja pelo lado do consumidor com ganhos de renda, quanto da massiva entrada dos vinhos importados, provenientes majoritariamente de países vizinhos e Europa, sugerem que o vinho se tornou um produto relevante dentro do segmento de bebidas alcoólicas e que este fenômeno merece uma investigação mais detalhada.

Desta forma, o objetivo deste trabalho consiste em analisar o mercado brasileiro de vinho e suas recentes mudanças do lado da demanda. 
Além disso, cabe destacar novamente que a dinâmica de consumo de vinho no Brasil não tem sido bem documentada (ver CAMPOS e BRIGATTE, 2007), e este trabalho também visa preencher esta lacuna na literatura. Uma das hipóteses que norteia esse trabalho é que o aumento na renda familiar, promovido pela estabilização da moeda e pelos programas de transferência de renda, tem contribuído para uma mudança de perfil de consumo entre as principais bebidas alcoólicas no País. Ademais, houve também outro efeito importante causado pela valorização do Real frente ao dólar, ocorrida de maneira mais acentuada entre os anos de 2002 a 2011, e que acabou por reduzir os preços dos vinhos importados, tornando o vinho nacional menos competitivo no mercado doméstico mesmo diante da elevada carga tributária que incide sobre os vinhos importados ${ }^{5}$. Assim, a estratégia empírica para analisar esses determinantes está baseada na estimativa de um sistema de demanda do tipo Almost ideal Demand System (AIDS) e de um Vetor Autorregressivo estrutural (VAR).

O texto está dividido em cinco seções. Além desta introdução, a seção 2 traz um breve panorama do setor vinícola no mundo e no Brasil, enquanto a terceira seção descreve a estratégica empírica adotada. Os resultados e conclusões do trabalho são apresentados nas seções 4 e 5, respectivamente.

\section{Panorama do setor vinícola}

A vitivinicultura brasileira começou com a chegada dos colonizadores portugueses. No entanto, foi só com os imigrantes italianos no final do século XIX e início do século XX que a produção de uvas e vinhos se tornou economicamente importante para o País (GUERRA et al., 2005). Em geral, as vinícolas, concentradas mais

5. Segundo dados do Instituto Brasileiro de Pesquisa Tributária, 83,4\% do preço pago no varejo por uma garrafa de vinho importando corresponde a tributos (Disponível em: < http://www.clubedoenofilo.com.br/2013/10/quanto-imposto-existe-no-vinho.html>. Acesso em: 26 jul. 2014). fortemente no Rio Grande do Sul, se aproveitavam de mão de obra familiar, contratando esporadicamente funcionários de fora da família. Esta característica manteve-se por um longo tempo. A produção aumentou à medida que se começou a produzir para o resto do Brasil, porém sem grandes mudanças na estrutura. A produção enviada para fora do Rio Grande do Sul encontrava mercado no Rio de Janeiro e em São Paulo, mas as quantidades vendidas eram pequenas (NIEROP, 2011). De acordo com os dados apresentados na Tabela 1, da International Organization of Vine and Wine (OIV), o Brasil figurou em 2012 entre os 20 países mais importantes do mundo na produção de vinho.

O Rio Grande do Sul é o maior produtor nacional de uvas, vinhos e outros derivados da fruta. O estado é responsável por 95\% da produção de uvas do Brasil (PROTAS et al., 2013).

A partir dos anos 1980, a variedade de uva "Itália" foi implantada com sucesso na região do semiárido brasileiro, mais especificamente no Vale do São Francisco. Este fato marcou o início da viticultura tropical no Brasil (PROTAS et al., 2013).

Desde meados da década de 1980, vinícolas brasileiras, localizadas no Sul do Brasil, têm investido em tecnologias para a produção de variedades de uvas europeias, bem como em processos de vinificação modernos, a fim de melhorar a qualidade do vinho nacional. Esses investimentos resultaram em muitos prêmios em provas nacionais e internacionais de vinhos (SATO e ANGELO, 2007).

O consumo de vinhos mundial era decrescente até o início dos anos 1990. Nesta década, o consumo mundial de vinho manteve-se relativamente estável, apesar de terem ocorrido algumas mudanças no mercado. De acordo com Teruchkin (2003), a mudança no mercado de vinhos experimentada a partir da década de 1990 pode ser atribuída às transformações nas relações de oferta e de demanda. Para ela, a principal mudança pelo lado da demanda ocorreu devido à redução no consumo de vinhos comuns nos principais países consumidores, dando lugar ao consumo de vinhos finos. Além disso, a autora também argumenta 
436 - A Demanda por Vinho no Brasil: elasticidades no consumo das famílias e determinantes da importação

Tabela 1. Maiores produtores mundiais de vinho (em milhões de hectolitros), entre 2009 e 2012

\begin{tabular}{lcccc}
\hline \multirow{2}{*}{ País* $^{*}$} & \multicolumn{4}{c}{ Quantidades } \\
\cline { 2 - 5 } & 2009 & 2010 & 2011 & 2012 \\
\hline 1. França & 46,269 & 44,322 & 50,757 & 41,422 \\
2. Itália & 47,314 & 48,525 & 42,772 & 40,060 \\
3. Espanha & 36,093 & 35,535 & 33,397 & 30,392 \\
4. EUA & 21,965 & 20,887 & 19,187 & 20,510 \\
5. China & 12,800 & 13,000 & 13,200 & 14,880 \\
6. Austrália & 11,784 & 11,420 & 11,180 & 12,660 \\
7. Chile & 10,093 & 8,844 & 10,464 & 12,554 \\
8. Argentina & 12,135 & 16,250 & 15,473 & 11,778 \\
9. África do Sul & 9,986 & 9,327 & 9,324 & 10,037 \\
10. Alemanha & 9,228 & 6,906 & 9,123 & 9,012 \\
11. Portugal & 5,868 & 7,133 & 5,610 & 6,141 \\
12. Romênia & 6,703 & 3,287 & 4,058 & 3,311 \\
13. Grécia & 3,366 & 2,950 & 2,750 & 3,150 \\
14. Brasil & 2,720 & 2,459 & 3,394 & 2,917 \\
\hline
\end{tabular}

* Ordenado segundo o ano de 2012.

Fonte: International Organization of Vine and Wine (OIV).

que houve crescimento no consumo de vinhos, principalmente os finos, em países que não têm tradição na produção, como o Brasil. Assim, um lento, mas sustentado, crescimento no consumo de vinhos finos de maior qualidade ocorreu a partir da década de 1990 em todos os mercados. A Tabela 2, abaixo, apresenta a evolução dos maiores países consumidores de vinhos entre 2009 e 2012, com o Brasil ocupando a $14^{\mathrm{a}}$ posição.
Glass e Castro (2009) analisam indicações geográficas como estratégia de mercado para agregação de valor à produção de vinho no Brasil. Os autores observaram, estudando o mercado do Distrito Federal por meio de aplicação de questionários, que as indicações geográficas são um fator de diferenciação do produto, que agrega valor aos vinhos, e que $57 \%$ dos consumidores estariam dispostos a pagar mais por vinhos que

Tabela 2. Maiores consumidores mundiais de vinho (em milhões de hectolitros) entre 2009 e 2012

\begin{tabular}{lcccc}
\hline \multirow{2}{*}{ País* $^{*}$} & \multicolumn{4}{c}{ Quantidades } \\
\cline { 2 - 4 } & 2009 & 2010 & 2011 & 2012 \\
\hline 1. França & 30,215 & 29,272 & 29,322 & 30,269 \\
2. EUA & 27,250 & 27,600 & 28,425 & 29,000 \\
3. Itália & 24,100 & 24,624 & 23,052 & 22,633 \\
4. Alemanha & 20,224 & 20,200 & 19,707 & 20,000 \\
5. China & 14,514 & 15,180 & 16,339 & 17,817 \\
6. Reino Unido & 12,680 & 12,900 & 12,860 & 12,533 \\
7. Rússia & 10,368 & 12,197 & 11,276 & 10,394 \\
8. Argentina & 10,342 & 9,753 & 9,809 & 10,051 \\
9. Espanha & 11,271 & 10,896 & 9,894 & 9,300 \\
10. Austrália & 5,120 & 5,351 & 5,325 & 5,375 \\
11. Portugal & 4,515 & 4,690 & 4,550 & 4,550 \\
12. Canada & 4,121 & 4,339 & 4,255 & 4,476 \\
13. África do Sul & 3,384 & 3,463 & 3,527 & 3,616 \\
14. Brasil & 3,508 & 3,686 & 3,805 & 3,399 \\
\hline
\end{tabular}

* Ordenado segundo o ano de 2012.

Fonte: International Organization of Vine and Wine (OIV). 
tivessem indicação geográfica. Em resposta a essa oportunidade de mercado, de acordo com Glass e Castro (2009), as vinícolas brasileiras têm procurado investir em indicações geográficas. Grande parte das vinícolas nacionais pesquisadas pelos autores (83\%) têm tomado iniciativas neste sentido.

Medina-Albaladejo et al. (2014) afirmam que o mercado mundial de vinhos tem enfrentado mudanças significativas nas últimas décadas. De acordo com os autores, estas mudanças seriam fruto do aumento de competitividade dos países exportadores do hemisfério sul, principalmente do Chile, a partir dos anos 1990, e da Argentina, na última década.

Além de Chile e Argentina, outros países se tornaram importantes no mercado internacional do produto, como EUA, Austrália e África do Sul, experimentando aumento da sua representatividade nas exportações mundiais. Como resultado, houve queda no preço médio dos vinhos comercializados no mercado internacional, além de maior variedade de produtos disponíveis ao consumidor.

A China vem ganhando importância no contexto global do mercado de vinhos. Capitello et al. (2015) estimaram a demanda por vinho importado pela China de acordo com a procedência, e para vinhos em garrafa, vinhos frisantes, entre outros. Por meio de um modelo AIDS, os autores avaliaram as importações provenientes da França, Itália, Austrália e Chile e do resto do mundo. Eles encontraram evidências que os vinhos franceses exercem o papel de líderes de mercado e que os vinhos frisantes apresentam elasticidade preço da demanda inelástica, enquanto que a elasticidade dos vinhos em garrafa varia de acordo com o tipo e procedência. Muhamad et al. (2014) confirmam que o vinho francês é líder de mercado na China e afirmam que cerca de um terço do total gasto em vinhos no país é proveniente deste destino. Já Xu et al. (2014) estudaram a disposição a pagar por vinhos tintos provenientes de diversas regiões e qualidades na China. Os resultados apontaram que o preço de venda continua sendo um fator-chave para a escolha dos consumidores daquele país.
A maior competitividade no mercado internacional de vinhos somada à abertura da economia brasileira aos produtos importados na década de 1990 levou a um aumento das importações de vinhos para o mercado brasileiro.

De acordo com Teruchkin (2003), paralelamente, passou a haver maior divulgação dos efeitos benéficos do consumo do vinho para a prevenção de doenças cardíacas coronárias e colesterol, que têm sido relatados e confirmados por especialistas e que também podem ter influenciado o aumento no consumo do produto. Por outro lado, outras bebidas alcoólicas, como a cerveja, investem grandes somas em publicidade visando aumentar o consumo, podendo levar à substituição do consumo do vinho em algumas ocasiões.

Para Roese (2008), a expansão da oferta de vinhos, além de promover um acesso cada vez maior ao consumo devido ao crescimento do comércio mundial, também transformou a produção e o consumo do produto. A principal mudança, para este autor, estaria relacionada com as preferências dos consumidores que influenciaram as decisões dos fornecedores e, portanto, o produto final. Ainda de acordo com Roese, as preferências dos consumidores têm sido influenciadas por novas referências. Estas se devem a um maior acesso do consumidor à informação, obtida, por exemplo, em reportagens veiculadas na imprensa e acesso à literatura e a críticos especializados, que no passado eram obtidas, quase que exclusivamente, via publicidade.

Cembalo et al. (2014) afirmam que os vinhos de qualidade superior têm expandido seus mercados em detrimento dos vinhos de qualidade mais básica. Entretanto, em países tradicionais na produção, estes vinhos mais básicos ainda têm participação importante no mercado, tanto em volume quanto em valor. Analisando o mercado destes vinhos de menor preço na Itália, os autores encontraram indícios de que a demanda responde significativamente ao nível de preços e que o tipo de embalagem também influencia na decisão de consumo. 
Segundo dados da International Organization of Vine and Wine (OIV), o consumo per capita de vinho no Brasil foi de 1,84 litro em 2011. Este nível de consumo pode ser considerado baixo quando comparado com países europeus, como França (46 litros), Portugal (44 litros) e Itália (38 litros). Mesmo quando comparado ao consumo de alguns países sul-americanos, o consumo per capita de vinho no Brasil também pode ser considerado baixo. O consumo de vinho da Argentina, do Uruguai, Chile e Paraguai foi 13, 11, 10 e 3 vezes, respectivamente, maior que o brasileiro em 2011.

Apesar de ser baixo em comparação com outros países, o consumo de vinho no Brasil tem apresentado crescimento consistente ao longo dos últimos anos, como pode ser visto na Figura 1. De acordo com dados da OIV, o consumo brasileiro se elevou de 1,49 litro per capita, em 1995, para 1,84 litro per capita em 2011. Isso representa taxa de crescimento de $1,3 \%$ ao ano ao longo do período.

De acordo com dado do Ministério do Desenvolvimento, Indústria e Comércio (MDIC), houve crescimento do quantum e do número de países que importam vinho proveniente do Brasil na última década. Conforme já mencionado, durante o período de 1995 a 2014, a importação de vinho brasileiro teve crescimento de $11,2 \%$ ao ano. Sato e Angelo (2007) argumentam que esse crescimento indica a internacionalização do setor, com uma participação significativa do vinho com mais qualidade e valor agregado usando variedades de uvas europeias.

Para os autores, o aumento das importações não tem prejudicado a indústria nacional, uma vez que a mesma passou a oferecer um produto de qualidade a preços competitivos. Este fato se deve, em grande parte, à evolução da indústria brasileira de vinhos no mesmo período. A serra gaúcha, principal região produtora no Brasil, tem tido crescimento tanto nas vendas domésticas quanto nas exportações. Este crescimento se reflete no número de vinícolas no Rio Grande do Sul que, conforme já destacado, cresceu de 439 em 2001 para 738 em 2009 (NIEROP, 2011).

Os dois principais fornecedores de vinho para o Brasil são países do Mercosul: Chile e Argentina. Outros países importantes no fornecimento de vinho para o mercado brasileiro são europeus: Itália, Portugal, França e Espanha (Tabela 3 e Figura 2).

Figura 1. Evolução do consumo per capita de vinho no Brasil - 1995 a 2011 - em litros por ano

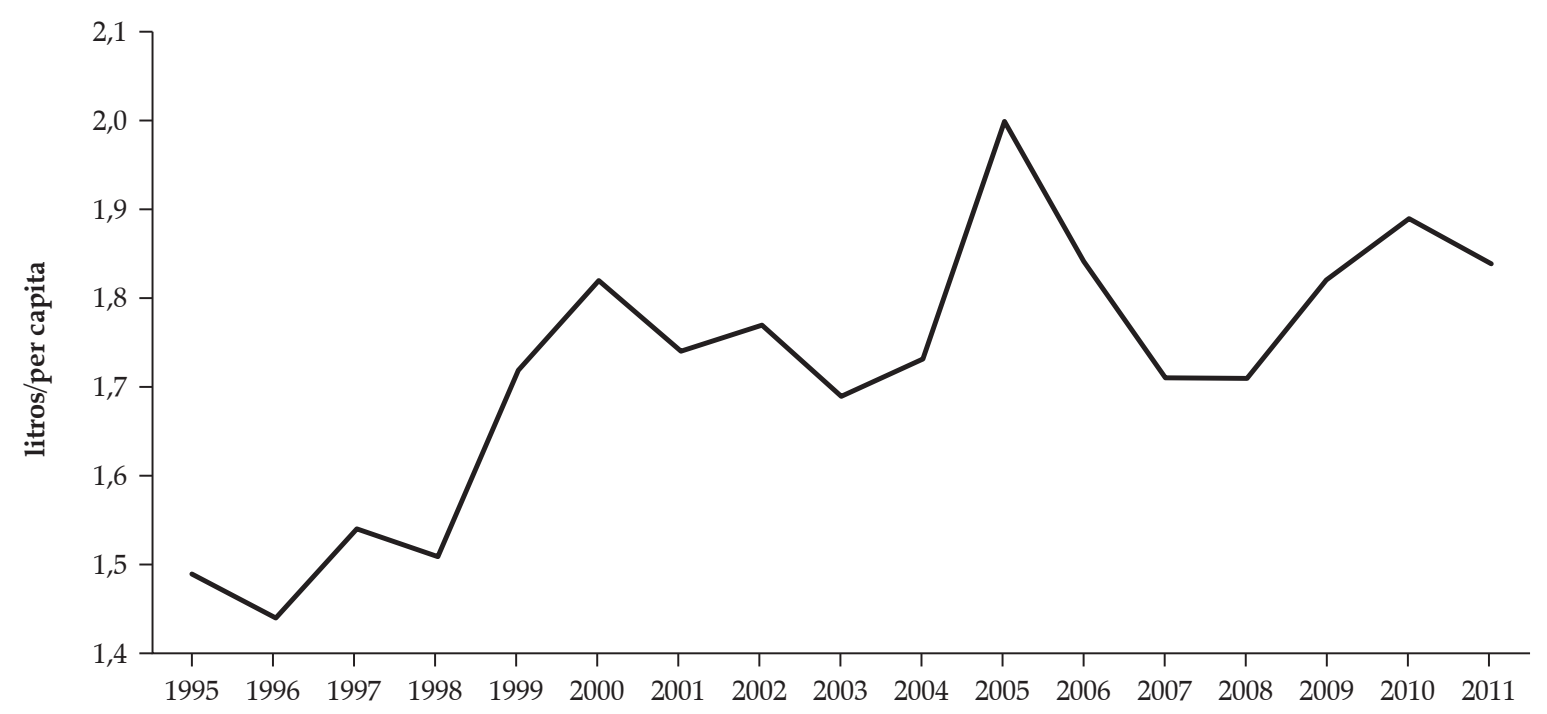

Fonte: International Organization of Vine and Wine (OIV), 2015. 
Tabela 3. Importação brasileira de vinho - principais países fornecedores - 2007 a 2014 - milhões de litros*

\begin{tabular}{ccccccccc}
\hline Ano & Chile & Argentina & Itália & Portugal & França & Espanha & Outros & Total \\
\hline 2007 & 18,89 & 16,18 & 10,41 & 6,85 & 3,82 & 1,12 & 3,60 & 60,87 \\
2008 & 18,75 & 15,43 & 10,77 & 6,28 & 3,46 & 1,26 & 1,96 & 57,91 \\
2009 & 22,52 & 14,80 & 9,09 & 5,98 & 3,50 & 1,51 & 1,81 & 59,21 \\
2010 & 26,51 & 18,05 & 13,00 & 8,08 & 4,27 & 2,13 & 3,28 & 75,32 \\
2011 & 26,71 & 17,67 & 13,16 & 8,61 & 5,13 & 2,83 & 3,52 & 77,63 \\
2012 & 30,40 & 15,58 & 11,64 & 9,79 & 5,03 & 3,59 & 3,51 & 79,54 \\
2013 & 28,41 & 13,43 & 9,29 & 9,37 & 4,76 & 3,62 & 3,34 & 72,22 \\
2014 & 35,56 & 14,24 & 9,66 & 9,80 & 4,82 & 3,69 & 2,97 & 80,74 \\
\hline
\end{tabular}

* A quantidade apresentada refere-se à soma dos seguintes códigos da Nomenclatura Comum do Mercosul (NCM) - NCM 22041010; NCM 22041090; NCM 22042100; NCM 22042900; NCM 22042911; NCM 22042919; NCM 22042920.

Fonte: Ministério do Desenvolvimento, Indústria e Comércio (MDIC), 2015.

Figura 2. Importação brasileira de vinhos - milhões de litros - 1997 a 2014

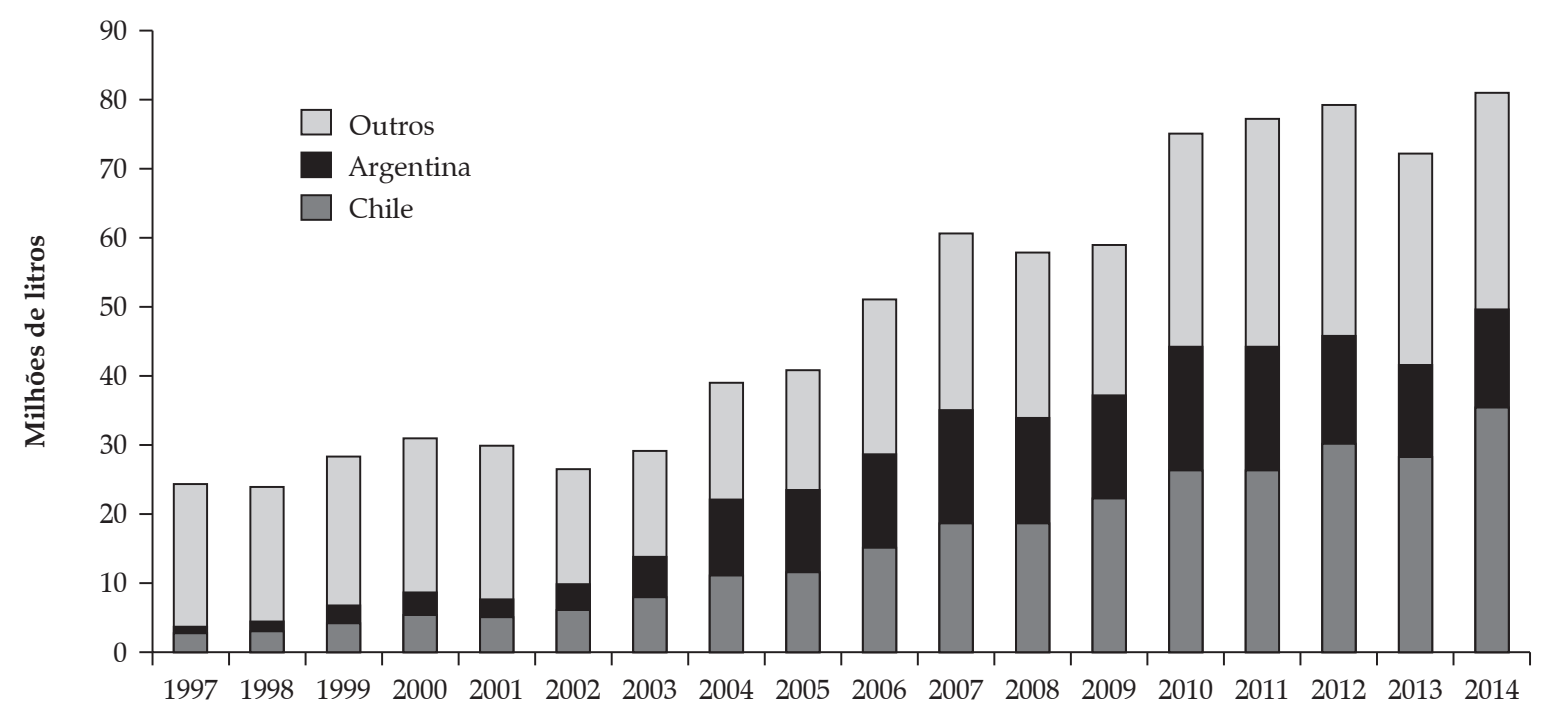

Fonte: Ministério do Desenvolvimento, Indústria e Comércio Exterior (MDIC), 2015.

A Tabela 4 apresenta a evolução entre 1995 e 2009 do consumo doméstico de vinho comparativamente com cerveja e outras bebidas alcoólicas por classes de renda. Esta tabela também inclui a renda média mensal para cada classe e o gasto mensal médio em Reais com bebidas alcoólicas. As estatísticas são provenientes da Pesquisa de Orçamentos Familiares do IBGE que serão utilizados no estudo. Primeiramente, pode-se observar que, em termos reais, o consumo de bebidas alcoólicas tem aumentado no País em todas as classes de renda ao longo do tempo. A cerveja representa a maior parte, acima de $55 \%$, seguido por outras bebidas alcoólicas e pelo vinho. É interessante observar que, entre as classes de renda intermediárias e mais altas, a parcela da renda utilizada para comprar vinho aumentou de $3 \%$ para $5 \%$, em média, entre 2003 e 2009. As estatísticas também sugerem haver uma relação de substitutibilidade entre vinho e outras bebidas alcoólicas, mas não entre vinho e cerveja, hipóteses que poderão ser corroboradas pela estimação do sistema de demanda a ser apresentado durante a análise dos resultados econométricos ao longo do artigo. 
Tabela 4. Gasto Mensal Domiciliar (R\$) e Gasto Mensal com Bebidas Alcoólicas (R\$) a preços constantes de 2013 por classe de renda no Brasil*

\begin{tabular}{|c|c|c|c|c|c|}
\hline \multirow{2}{*}{$\begin{array}{l}\text { Classes de } \\
\text { Renda }\end{array}$} & \multirow{2}{*}{$\begin{array}{c}\text { Gasto Mensal } \\
\text { domiciliar (R\$) }\end{array}$} & \multirow{2}{*}{$\begin{array}{c}\text { Gasto Mensal domiciliar (R\$) } \\
\text { com bebidas alcoólicas }\end{array}$} & \multicolumn{3}{|c|}{$1996^{* *}$} \\
\hline & & & Cervejas & Outras & Vinho \\
\hline Octile 1 & 349,99 & 5,20 & $55,6 \%$ & $41,4 \%$ & $3,0 \%$ \\
\hline Octile 2 & 760,39 & 13,95 & $77,6 \%$ & $19,5 \%$ & $2,9 \%$ \\
\hline Octile 3 & $1.130,73$ & 23,64 & $82,3 \%$ & $14,7 \%$ & $3,0 \%$ \\
\hline Octile 4 & $1.559,95$ & 32,97 & $86,7 \%$ & $11,5 \%$ & $1,8 \%$ \\
\hline Octile 5 & $2.051,83$ & 39,92 & $83,4 \%$ & $13,5 \%$ & $3,1 \%$ \\
\hline Octile 6 & $2.973,79$ & 56,67 & $86,6 \%$ & $11,1 \%$ & $2,3 \%$ \\
\hline Octile 7 & $4.951,88$ & 72,68 & $80,9 \%$ & $15,7 \%$ & $3,4 \%$ \\
\hline \multirow[t]{3}{*}{ Octile 8} & $14.529,42$ & 91,27 & $77,0 \%$ & $17,4 \%$ & $5,6 \%$ \\
\hline & & & \multicolumn{3}{|c|}{2003} \\
\hline & & & Cervejas & Outras & Vinho \\
\hline Octile 1 & 514,07 & 6,11 & $64,2 \%$ & $33,1 \%$ & $2,7 \%$ \\
\hline Octile 2 & $1.109,73$ & 16,06 & $78,8 \%$ & $18,7 \%$ & $2,6 \%$ \\
\hline Octile 3 & $1.528,99$ & 23,36 & $82,1 \%$ & $14,9 \%$ & $3,1 \%$ \\
\hline Octile 4 & $2.032,30$ & 32,07 & $83,2 \%$ & $13,3 \%$ & $3,6 \%$ \\
\hline Octile 5 & $2.717,75$ & 41,50 & $85,9 \%$ & $10,1 \%$ & $4,1 \%$ \\
\hline Octile 6 & $3.713,45$ & 51,48 & $85,1 \%$ & $10,8 \%$ & $4,1 \%$ \\
\hline Octile 7 & $5.642,22$ & 58,25 & $85,6 \%$ & $10,4 \%$ & $4,0 \%$ \\
\hline \multirow[t]{3}{*}{ Octile 8} & $13.122,51$ & 90,04 & $77,0 \%$ & $13,8 \%$ & $9,1 \%$ \\
\hline & & & \multicolumn{3}{|c|}{2009} \\
\hline & & & Cervejas & Outras & Vinho \\
\hline Octile 1 & 517,39 & 5,55 & $69,1 \%$ & $27,2 \%$ & $3,7 \%$ \\
\hline Octile 2 & $1.083,26$ & 11,98 & $83,1 \%$ & $12,7 \%$ & $4,2 \%$ \\
\hline Octile 3 & $1.484,82$ & 17,56 & $83,7 \%$ & $12,4 \%$ & $3,9 \%$ \\
\hline Octile 4 & $1.936,46$ & 22,77 & $83,4 \%$ & $11,4 \%$ & $5,2 \%$ \\
\hline Octile 5 & $2.499,11$ & 27,61 & $86,4 \%$ & $8,9 \%$ & $4,6 \%$ \\
\hline Octile 6 & $3.376,57$ & 35,70 & $87,1 \%$ & $7,8 \%$ & $5,1 \%$ \\
\hline Octile 7 & $5.068,68$ & 44,65 & $82,7 \%$ & $10,0 \%$ & $7,3 \%$ \\
\hline Octile 8 & $12.443,56$ & 60,26 & $77,8 \%$ & $10,2 \%$ & $12,0 \%$ \\
\hline
\end{tabular}

* Valores atualizados utilizando o deflator de rendimentos da PNAD-INPC (R\$ = Base 2013) (CORSEUIL e FOGUEL, 2002). Fonte: www.ipeadata.gov.br. ** A POF 1996 inclui as nove regiões metropolitanas mais populosas do País, acrescido do DF e Goiânia.

Fonte: Microdados das POFs (elaboração dos autores).

Um grande número de autores internacionais se dedicou a estimar as elasticidades do preço do vinho e da cerveja, bem como a elasticidade renda do consumo de vinho. Gallet (2007), por exemplo, fez uma síntese de 132 trabalhos que visavam estimar algumas destas elasticidades em diferentes países, incluindo trabalhos realizados de 1958 até 2003. A mediana para a elasticidade preço da demanda para o vinho e para a cerveja, baseada neste conjunto de trabalhos, foi de, respectivamente, $-0,70$ e -0,36. Embora os resultados de Gallet (2007) apontem para uma elasticidade preço do vinho maior que para a cerveja, alguns autores encontraram resultados opostos. Meng et al. (2014), por exemplo, estimaram as elasticidades preços própria e cruzada da demanda por várias bebidas alcóolicas no Reino Unido. As elasticidades preço encontradas foram todas negativas, sendo que a da cerveja foi mais elástica do que a do vinho (-0,98 e -0,38, respectivamente).

Quanto à elasticidade renda, Gallet (2007) encontrou medida para sua amostra de 1,10 para o vinho e 0,40 para a cerveja. O autor argumenta que os valores encontrados variam bastante de acordo com os locais considerados e os métodos empregados na análise. 
No que tange às elasticidades cruzadas entre bebidas alcóolicas, também há algumas diferenças entre os trabalhos disponíveis na literatura. As elasticidades preço cruzadas encontradas por Meng et al. (2014) foram inferiores em magnitude quando comparadas às elasticidades diretas, apresentando sinais positivos e negativos dependendo do caso. Syrovatka et al. (2014) também calcularam as elasticidades preço cruzada do vinho em relação à cerveja, rum e outras bebidas na República Tcheca. Os cálculos foram feitos para vários períodos, sendo que a média das elasticidades preço cruzadas do vinho e da cerveja foram de $-0,28$ e do vinho e do rum, de -0,21.

\section{Estratégia econométrica}

A estratégia empírica é baseada na estimativa de um modelo Almost Ideal Demand System (AIDS) e um Vetor Autorregressivo (VAR) estrutural.

$\mathrm{O}$ trabalho foi dividido em duas etapas. O primeiro passo é analisar a demanda doméstica no consumo de vinho e a substituição com relação a outras bebidas com base nas Pesquisas de Orçamentos Familiares (POFs) do IBGE. A segunda é investigar a influência da taxa de câmbio, dos preços e da renda sobre a importação de vinhos.

\subsection{Almost Ideal Demand System (AIDS)}

Deaton e Muellbauer (1980) desenvolveram um sistema de demanda flexível, chamado Almost Ideal Demand System (AIDS). O conceito de um sistema de demanda flexível é extremamente útil para estimar um sistema de demanda com muitas propriedades desejáveis. Conforme Moschini (1998), o modelo AIDS satisfaz a restrição de agregação e, com a agregação de restrições paramétricas simples, homogeneidade e simetria podem ser facilmente impostas. Além disso, as curvas não lineares de Engel do modelo AIDS implicam que um aumento na renda leva a uma diminuição na parcela de renda destinada ao consumo de um determinado bem e também a uma diminuição da elasticidade-renda do bem quando esta for inferior a um.

A função demanda pelo modelo AIDS é especificada como ${ }^{6,7}$ :

$$
w_{i}=\alpha_{i}+\sum_{j=1}^{n} \gamma_{i j} \log p_{j}+\beta_{i} \log (X P)
$$

em que $\mathrm{w}_{\mathrm{i}}$ á participação do $i$-ésimo bem na despesa total, $\mathrm{p}_{\mathrm{j}}$ é o preço do j-ésimo bem, $\alpha_{\mathrm{i}}, \gamma_{\mathrm{ij}}$ e $\beta_{\mathrm{i}}$ são parâmetros a serem estimados. Finalmente, a despesa total $(X)$ é dada por:

$$
X=\sum_{i=1}^{n} p_{i} q_{i}
$$

em que $q_{\mathrm{i}}$ é a quantidade demandada pelo $i$-ésimo bem. O índice de preços $(P)$ é dado por:

$$
\log \mathrm{P}=\alpha_{0}+\sum_{\mathrm{i}=1}^{\mathrm{n}} \mathrm{a}_{\mathrm{i}} \log \mathrm{p}_{\mathrm{i}}+\frac{1}{2} \sum_{\mathrm{i}=1}^{\mathrm{n}} \sum_{j=1}^{\mathrm{n}} \gamma_{\mathrm{ij}} \log \mathrm{p}_{\mathrm{i}} \log \mathrm{p}_{\mathrm{j}}
$$

no modelo AIDS não linear. Entretanto, ele pode ser especificado como um índice de preços linear dado por:

$$
\log \mathrm{P}=\sum_{\mathrm{i}=1}^{\mathrm{n}} \mathrm{W}_{\mathrm{i}} \ln \mathrm{p}_{\mathrm{i}}
$$

Esta forma é conhecida como aproximação linear do modelo AIDS (LA-AIDS) (BUSE, 1994).

No modelo AIDS não linear, a ser estimado pelo presente estudo, restrições nos parâmetros podem ser aplicadas em (1), tais como aditividade (5), homogeneidade (6) e simetria (7) para os $i$ produtos, que podem ser representados por:

$$
\begin{aligned}
& \sum_{i=1}^{n} \alpha_{i}=1, \quad \sum_{i=1}^{n} \beta_{i}=0, \quad \sum_{i=1}^{n} \gamma_{i j}=0 \\
& \sum_{j=1}^{n} \gamma_{i j}=0 \\
& \gamma_{i j}=\gamma_{j i}
\end{aligned}
$$

Com base nos coeficientes estimados em (1), as equações para a elasticidade Marshaliana, renda e a elasticidade Hicksiana, para o bem $i$, podem ser representadas, respectivamente por:

6. SAS Customer Support Center. Estimating an Almost Ideal Demand System Model, URL http://support.sas.com/rnd/ app/examples/ets/aids/index.htm

7. SAS Customer Support Center. Calculating elasticities in an almost ideal demand system, URL http://support.sas. com/rnd/app/examples/ets/elasticity/ 


$$
e_{i j}^{M}=\frac{\gamma_{i j}-\beta_{i}\left(w_{j}-\beta_{j} \ln \left(\frac{X}{P}\right)\right)}{w_{i}}-\delta_{i j}
$$

Em que $\delta_{i j}=1$ se $i=j$ e $\quad \delta_{i j}=0 \quad$ se $i \neq j$

$$
\begin{gathered}
e_{i}=1+\frac{\beta_{i}}{w_{i}} \\
e_{i j}^{H}=e_{i j}^{M}-w_{i j} e_{i}
\end{gathered}
$$

Configura-se com uma das vantagens que as restrições de homogeneidade e simetria são facilmente impostas durante a estimação do modelo AIDS (PINTOS-PAYERAS, 2009).

As bases de dados utilizadas para a estimação do modelo AIDS são provenientes de tabulações especiais dos microdados das Pesquisas de Orçamentos Familiares (POF), realizada pelo Instituto Brasileiro de Geografia e Estatística (IBGE) entre outubro de 1995 e setembro de 1996, entre julho de 2002 e junho de 2003 e novamente entre maio de 2008 e maio de 2009. As POFs permitem diagnosticar a qualidade de vida das famílias brasileiras com base, principalmente, no seu orçamento doméstico (IBGE, 2004).

As POFs 95/96, 02/03 e 08/09 entrevistaram $16.013,48.470$ e 55.970 unidades domiciliares, respectivamente, sendo que a primeira cobriu apenas as nove regiões metropolitanas, Goiânia e Distrito Federal. Para a realização da pesquisa partiu-se dos resultados do censo demográfico de 1991, no caso da POF 96/06, e do Censo Demográfico de 2000 para as duas últimas edições (IBGE, 2004; IBGE, 2010). Os fatores de expansão, que representam o universo amostral das POFs, são construídos com base na contagem populacional de 1996 e do censo demográfico de 2000. Para manter a consistência com a primeira edição da POF, 95/96, apenas os dados das regiões metropolitanas, Goiânia e DF das duas últimas edições foram utilizados no presente estudo.

Na maior parte dos estudos sobre demanda faz-se também necessário o uso de preços dos principais bens que compõem a cesta de consumo das famílias. Entretanto, quase sempre eles não são disponibilizados periodicamente pelos órgãos oficiais ${ }^{8}$. Dentro das POFs existe uma caderneta de despesa coletiva que engloba itens alimentícios e produtos de limpeza. Esse é o único registro da POF que possui não somente as despesas, mas também as quantidades adquiridas. Com isso, é possível calcular os preços (implícitos) dos alimentos, isto é, a despesa dividida pela quantidade do respectivo bem.

As POFs são riquíssima fonte de informação, mas apresentam muitas limitações, naturais em levantamentos de tão complexa execução (IBGE, 2010). Observa-se elevada presença de despesas com valor zero, inclusive para itens de consumo frequente, como alimentos. Dois fatores concorrem para tanto. Em primeiro lugar, o gasto pode não ter sido realizado durante o período da entrevista, embora isto não queira dizer que o bem não tenha sido consumido (pois a família poderia ter esses itens em estoque, por exemplo). Em segundo, pode ser que o bem simplesmente não faça parte da cesta de consumo do domicílio, por hábito, renda etc. Para remediar o problema gerado pela ausência dessas informações, a solução adotada neste trabalho foi agregar as famílias por classes de renda, uma prática bastante comum em estudos de demanda (MENEZES et al., 2007). ${ }^{9}$ Assim, para o estudo, as famílias foram agregadas em oito classes de renda, de acordo com a despesa monetária mensal total. Em outras palavras, em cada cidade foram construídos oito domicílios representativos, que representam as médias dos domicílios inseridos nas respectivas

8. ftp://ftp.ibge.gov.br/Precos_Indices_de_Precos_ao_ Consumidor/Sistema_de_Indices_de_Precos_ao_ Consumidor/Precos_Medios/

9. Alternativamente, em trabalhos mais recentes sobre sistemas de demanda, tem sido adotado um método em dois estágios proposto por Shonkwiller e Yen (1999) para corrigir o problema de consumo zero resultado do viés de seleção amostral (ALVES et al., 2007; COELHO e AGUIAR, 2007; SILVA e COELHO, 2014). É certo que tal procedimento seria o mais adequado para estimar um sistema de demanda para a maior parte dos alimentos e bebidas, mas não seria o caso para o presente estudo, considerando que existe também uma parcela da população que não consome bebidas alcoólicas por motivos religiosos ou por outra opção não observável ao econometrista e, portanto, não poderia entrar na análise. 
classes de renda. Foram geradas, assim, 88 observações (8 classes de renda vezes 11 localidades) para cada ano. Especificamente, foram usadas informações de 16.013 domicílios da POF 95/06, 6.573 da de 2002/03 e 8.575 da de 2008/09.

\subsection{Vetor Autorregressivo Estrutural (VAR)}

Os procedimentos econométricos adotados foram testes de raiz unitária e um modelo de Vetor Autorregressivo Estrutural (VAR), que compreende a estimação da função de impulso resposta e a análise da decomposição histórica da variância. O sistema que compõe o modelo VAR estrutural proposto para a importação brasileira de vinhos é composto de quatro variáveis: taxa de câmbio efetiva real, renda nacional, preços médios de importação e quantidade importada ${ }^{10}$. O período de análise estende-se de janeiro de 1995 a março de 2015. O teste utilizado para se determinar a existência de raiz unitária nas séries foi o desenvolvido por Elliott, Rothenberg e Stock (1996), conhecido como DF-GLS. ${ }^{11}$

\section{Resultados e discussão}

Nesta seção serão apresentados e discutidos os resultados, tanto para o modelo AIDS quanto para o VAR estrutural. As regressões do modelo AIDS estão em anexo.

\subsection{Resultados do modelo AIDS - Elasticidades no consumo das famílias}

Os resultados das elasticidades Marshaliana, renda e Hicksiana provenientes da estimação do modelo AIDS utilizando os três anos disponíveis das POFs estão apresentados nas tabelas

10. Ressalta-se que a inclusão de outras variáveis como consumo total e outras especificações para a taxa de câmbio foram testadas.

11. Outros testes de estacionariedade e testes para se verificar a presença de quebra estrutural no modelo foram realizados e estão disponíveis para consulta. Os resultados destes testes adicionais de estacionariedade não diferiram muito dos resultados encontrados no teste DF-GLS.
5, 6 e 7, respectivamente. As regressões estão no anexo, considerando oito classes de renda para as nove regiões metropolitanas, acrescido do DF e Goiânia. Variáveis binárias de controle temporal e regional também foram incluídas no modelo. As elasticidades foram então calculadas através das equações 8, 9 e 10 apresentadas na seção metodológica com base nos coeficientes estimados do modelo ${ }^{12}$. Os resultados mostram que a elasticidade-preço da demanda para o vinho é de cerca de 0,71 , enquanto as elasticidades-preço para outras bebidas alcoólicas é de 0,29 e de 0,98 para a cerveja (Tabela 5), o que sugere que a demanda por vinho e por outras bebidas é bem menos elástica a preço que a demanda por cerveja, ou seja, o consumidor brasileiro de vinho e de outras bebidas é muito menos sensível a variações de preços que o consumidor brasileiro de cerveja. Esse resultado também pode ser consequência, ainda, do tamanho do mercado dessas duas bebidas, que é bem menor que o mercado de cerveja. É importante ressaltar também que, na análise, o consumidor está indiferente entre um produto importado e nacional, já que pelos dados da POF não é possível saber o país de origem do produto adquirido.

As elasticidade-cruzadas, por sua vez, sugerem que, no consumo de cerveja, há uma relação de complementaridade entre vinho e cerveja, e de substitutabilidade em relação a outras bebidas. Em outras palavras, um aumento de $1 \%$ no preço de cerveja tende a diminuir o consumo de vinhos em cerca de $0,013 \%$, ao passo que o aumento no preço de outras bebidas é de $0,056 \%$. Já no consumo de vinho, a relação identificada foi de substitutibilidade para ambos os grupos, ou seja, um aumento de $1 \%$ no preço de vinho aumenta o consumo de cervejas em $0,088 \%$, e o consumo

12. Como testes de robustez dos dados, as três medidas de elasticidades consideradas também foram calculadas usando os dois últimos anos da POF 2003 e 2009, mas agora incluindo todas as famílias urbanas agrupadas em oito classes de renda de todos os estados da federação. Os resultados dessas elasticidades não se diferenciaram substancialmente quando foram considerados somente as RMs, DF e Goiânia. As elasticidades com base nos coeficientes estimados pelo modelo AIDS estão no anexo. 
de outras bebidas, em 0,103\%. Já uma elevação de $1 \%$ no preço de outras bebidas tende a gerar aumento no consumo de cervejas $(0,19 \%)$ e no consumo de vinho $(0,077 \%)$.

Em relação à elasticidade-renda (Tabela 6) foi encontrado 0,83 para o vinho, 0,86 para a cerveja e 0,60 para outras bebidas. Estes resultados sugerem que o crescimento da renda tem maior capacidade de influenciar o consumo de vinho do que de outras bebidas alcoólicas e, quase na mesma proporção, o consumo de cervejas. Assim, o aumento da renda esperado tende a ter impacto maior sobre o crescimento do mercado de vinho e cervejas no Brasil do que no mercado de outras bebidas alcoólicas, sinalizando maior preferência do consumidor e oportunidades de negócios para o setor produtivo das duas primeiras do que da última.

A elasticidade Hicksiana considera o efeito sobre o bem-estar do consumidor de variações de preços dos produtos. Essa elasticidade é, por vezes, chamada de elasticidade compensada. Nesse caso (Tabela 7), o resultado é relativamente diferente do visto para o caso da demanda marshaliana. A demanda por cerveja é mais inelástica que a demanda por vinho $(-0,39$ contra $-0,58$, res- pectivamente). Isso se deve ao fato de que entre as famílias que consomem bebidas alcoólicas o peso da cerveja no orçamento é bem maior do que o peso do vinho (Tabela 4). Nesse caso, como o consumidor prefere muito mais cerveja que vinho, nas condições atuais, para preservar seu nível de bem-estar (utilidade) ele aceitará maiores variações no preço da cerveja, sem reduzir muito seu consumo. Cabe ressaltar que é possível também que este fato não esteja relacionado a uma questão de preferência, mas sim ao fato de a cerveja ser mais barata, e representar uma parcela maior nos gastos das famílias, uma hipótese a ser investigada por estudos futuros.

No que se refere à elasticidade-cruzada, no entanto, os resultados modificam o verificado anteriormente, de eventual complementaridade entre vinho e cerveja, em função dos efeitos sobre a renda de mudanças nos preços relativos. Se o preço da cerveja subir $1 \%$, o consumo de vinhos e de outras bebidas terá aumento de 0,467\% e $0,56 \%$, respectivamente, para manter o consumidor no mesmo nível de utilidade. Essa relação de substitutibilidade também se verifica se ocorrer aumento no preço do vinho e da cerveja, mas em menor proporção.

Tabela 5. Matriz de elasticidade marshalliana

\begin{tabular}{|c|c|c|c|c|}
\hline \multirow{2}{*}{\multicolumn{2}{|c|}{ Produto }} & \multicolumn{3}{|c|}{ Variação exógena no preço } \\
\hline & & Cerveja & Outras bebidas alcoólicas & Vinho \\
\hline \multirow{3}{*}{$\begin{array}{l}\text { Variação endógena na } \\
\text { quantidade }\end{array}$} & Cerveja & $-0,989$ & 0,190 & 0,088 \\
\hline & Outras bebidas & 0,056 & $-0,297$ & 0,103 \\
\hline & Vinho & $-0,013$ & 0,077 & $-0,712$ \\
\hline
\end{tabular}

Fonte: Dados da pesquisa com base nos resultados econométricos.

Tabela 6. Elasticidade-renda

\begin{tabular}{lc}
\hline \multicolumn{1}{c}{ Produto } & Elasticidade-Renda \\
\hline Cerveja & 0,86 \\
Outras bebidas alcoólicas & 0,60 \\
Vinho & 0,83 \\
\hline
\end{tabular}

Fonte: Dados da pesquisa com base nos resultados econométricos. 
Tabela 7. Matriz de elasticidades Hicksianas

\begin{tabular}{|c|c|c|c|c|}
\hline \multirow{2}{*}{\multicolumn{2}{|c|}{ Produto }} & \multicolumn{3}{|c|}{ Variação exógena no preço } \\
\hline & & Cerveja & Outras bebidas alcóolicas & Vinho \\
\hline \multirow{3}{*}{$\begin{array}{l}\text { Variação endógena na } \\
\text { quantidade }\end{array}$} & Cerveja & $-0,398$ & 0,336 & 0,217 \\
\hline & Outras bebidas & 0,467 & $-0,196$ & 0,192 \\
\hline & Vinho & 0,559 & 0,218 & $-0,587$ \\
\hline
\end{tabular}

Fonte: Dados da pesquisa com base nos resultados econométricos.

\subsection{Resultados do modelo VAR - Determinantes da importação}

As séries para os preços de importação e para as quantidades importadas utilizadas no cálculo do modelo VAR foram obtidas a partir do sistema Aliceweb do Ministério do Desenvolvimento, Indústria e Comércio (MDIC), com periodicidade mensal, cobrindo o período compreendido entre janeiro de 1995 e março de 2015. A quantidade importada, ilustrada na Figura 2, foi obtida diretamente das informações disponíveis, enquanto que os preços médios de importação foram obtidos dividindo-se o valor total das importações pela quantidade. Utilizou-se a taxa de câmbio efetiva real calculada pelo Instituto de Pesquisa Econômica Aplicada (Ipea), no mesmo período das quantidades e preços das importações de vinho. Empregou-se como proxy para a renda a estimativa mensal de Produto Interno Bruto, divulgada pelo Banco Central. Por fim, cabe ressaltar que todas as variáveis descritas entraram no modelo em logaritmos neperianos e em índices.
A seguir, são descritos os resultados dos testes de raízes unitárias para em seguida discutir os resultados dos testes de cointegração. Depois, os coeficientes da matriz $\mathrm{A}_{0}$ do modelo VAR estrutural são analisados. Finalmente, a decomposição dos erros de previsão e as funções de impulso resposta do modelo VAR são apresentadas.

Na Tabela 8 estão os resultados dos testes DF-GLS $\tau$ com e sem a inclusão de tendência em que a hipótese nula é a presença de raiz unitária.

O teste DF-GLS $\tau$ com e sem inclusão de tendência determinística para a taxa de câmbio, renda e quantidade importada indica que as hipóteses nulas da presença de raiz unitária não podem ser rejeitadas a $1 \%, 5 \%$ ou $10 \%$ de significância. Assim, os testes DF-GLS $\tau$ indicaram que as séries taxa de câmbio, renda e quantidade importada têm uma raiz unitária.

O teste DF-GLS $\tau$ com a inclusão de uma constante e uma tendência determinística para os preços de importação indicou que a hipótese nula de presença de raiz unitária não é rejeitada a 10\%, mas é rejeitada a 5\% de significância. Assim,

Tabela 8. Resultados dos testes de raiz unitária DF-GLS $\tau$ com e sem tendência

\begin{tabular}{lcccccc}
\hline \multirow{2}{*}{ Variável } & \multirow{2}{*}{ Tendência } & \multirow{2}{*}{ Defasagem } & Estatística $t$ & \multicolumn{3}{c}{ Valores críticos } \\
\cline { 5 - 8 } Taxa de câmbio & Não & 2 & $-0,37$ & $\mathbf{1 \%}$ & $\mathbf{5 \%}$ & $\mathbf{1 0 \%}$ \\
\hline \multirow{2}{*}{ Renda } & Sim & 2 & $-1,82$ & $-1,57$ & $-1,64$ & $-3,62$ \\
& Não & 1 & $-0,10$ & $-2,57$ & $-1,94$ & $-1,62$ \\
\multirow{2}{*}{ Preços de importação } & Sim & 4 & $-1,90$ & $-3,48$ & $-2,89$ & $-2,57$ \\
\hline \multirow{2}{*}{ Quantidade importada } & Não & 4 & $-0,01$ & $-2,57$ & $-1,94$ & $-1,62$ \\
& Sim & 5 & $-2,59$ & $-3,48$ & $-2,89$ & $-2,57$ \\
\hline
\end{tabular}

Fonte: Dados da pesquisa com base nos resultados econométricos. 
os resultados encontrados apontam que a série tem uma raiz unitária a 10\% de significância. Sem a inclusão de uma tendência determinística, o teste indicou que a hipótese nula de presença de raiz unitária não é rejeitada a $1 \%, 5 \%$ ou $10 \%$ de significância.

Desta forma, os resultados dos testes DF-GLS $\tau$ apontaram para a necessidade de incluir todas as variáveis em diferença no modelo VAR estrutural. O fato de que as variáveis são integradas de mesma ordem levou à necessidade de se testar a existência de integração entre elas e à adição de um termo de correção de erros no modelo estrutural proposto VAR, o que foi feito utilizando o procedimento de Johansen (1988). Os valores críticos para os testes são apresentados por Osterwald-Lenun (1992).

Como pode ser visto na Tabela 9, a hipótese de não existência de cointegração $(r=0)$ é rejeitada ao nível de significância de 5\%. A estatística $\lambda_{\text {traço }}$ apresenta valor de 108,6 , que excede o valor crítico de 47,7 .

A hipótese $r \leq 1$ para os vetores de cointegração também é rejeitada a 5\% de significância, uma vez que o $\lambda_{\text {traço }}$ tem um valor maior do que o crítico (42,9 e 29,8, respectivamente) (Tabela 10).

A hipótese de que há $r \leq 2$ vetores de cointegração não pode ser rejeitada. Como pode ser visto também na Tabela 10, o valor obtido para a estatística $\lambda_{\text {traço }}$ foi de 9,5 , que é menor do que o valor crítico de Osterwald-Lenun (1992) ao nível de significância de 5\%, que é de 15,4. Assim, o teste indicou a existência de dois vetores de cointegração no VAR estrutural.

$\mathrm{O}$ teste AIC para o número de defasagens para o sistema VAR mostrou que o melhor modelo é aquele com oito defasagens.

Na Tabela 10 os resultados da matriz $\mathrm{A}_{0}$ do modelo VAR são apresentados. As relações contemporâneas têm os sinais esperados. Como se pode avaliar, a taxa de câmbio $\left(a_{41}\right)$ e preço de importação $\left(a_{43}\right)$ têm impactos negativos sobre as quantidades importadas, ou seja, um aumento na magnitude dessas variáveis gera uma diminuição na quantidade de vinho importado, ao mesmo tempo em que aqueles acontecem. Por outro lado, a renda $\left(a_{42}\right)$ tem um impacto positivo na quantidade importada, ou seja, um aumento na renda nacional gera um aumento na quantidade de vinhos importados.

Campos e Briggate (2008) ajustaram um modelo de Nerlove entre a quantidade importada de vinho versus a quantidade importada do período anterior, PIB, preço de importação e taxa de câmbio a partir de dados mensais provenientes das bases disponibilizadas por Aliceweb, Bacen e Secex entre 1995 e 2007. Em conjunto, as variáveis independentes explicaram $52 \%$ das variações na demanda por vinho importado. Similar ao nosso trabalho, renda e preço também apresentaram sinais esperados, o mesmo não ocorrendo para a taxa de câmbio. Além disso, no trabalho dos autores, a quantidade de vinho importado defasada

Tabela 9. Teste de cointegração das variáveis

\begin{tabular}{cccc}
\hline Hipótese nula & Hipótese alternativa & $\lambda_{\text {traço }}$ & Valores críticos de Osterwald-Lenun (1992) \\
\hline $\mathrm{r}=0$ & $\mathrm{r}>0$ & 108,571 & 47,707 \\
$\mathrm{r} \leq 1$ & $\mathrm{r}>1$ & 42,947 & 29,804 \\
$\mathrm{r} \leq 2$ & $\mathrm{r}>2$ & 9,488 & 15,408 \\
$\mathrm{r} \leq 3$ & $\mathrm{r}>3$ & 2,258 & 3,841 \\
\hline
\end{tabular}

Fonte: Dados da pesquisa com base nos resultados econométricos.

Tabela 10. Coeficientes, erro padrão, estatística t e significância das relações contemporâneas do modelo VAR

\begin{tabular}{ccccc}
\hline Variável & Coeficiente & Erro padrão & Estatística $t$ & Significância \\
\hline $\mathrm{a}_{41}$ & $-0,064$ & 0,392 & $-0,163$ & 0,871 \\
$\mathrm{a}_{42}$ & 4,743 & 0,441 & 10,759 & 0,000 \\
$\mathrm{a}_{43}$ & $-1,143$ & 0,168 & $-6,807$ & 0,000 \\
\hline
\end{tabular}

Fonte: Dados da pesquisa com base nos resultados econométricos. 
de um período apresentou sinal positivo e estatisticamente significativo.

A Tabela 11 apresenta a decomposição da variância dos erros de previsão da quantidade importada para dez períodos à frente.

Os resultados mostram que cerca de $30 \%$ da variação de quantidade pode ser explicada por variações na renda. Os preços dos vinhos importados correspondem a cerca de $20 \%$ destas variações. Por outro lado, a taxa de câmbio não mostra a mesma importância para explicar a variância da importação de vinhos. A parte não explicada da variância da quantidade sugere que poderiam existir outras variáveis importantes para explicar as importações que não foram consideradas no modelo. Uma possível explicação reside na possibilidade de que tenha havido uma mudança nas preferências dos consumidores que, ao longo do tempo, trocaram o consumo de vinhos nacionais por vinhos importados provenientes de países com maior tradição na produção.

As Figuras 3, 4 e 5 mostram as respostas na quantidade importada provenientes de choques oriundos de variações na renda, na taxa de câmbio e no preço de importação. Uma vez que os dados estão em logaritmos, os resultados de impulso-resposta apresentados podem ser analisados como elasticidades.

Tabela 11. Decomposição da variância dos erros de previsão para a série de quantidade importada

\begin{tabular}{ccccc}
\hline Período & Taxa de câmbio & Renda & Preço & Quantidade \\
\hline 1 & 0,01 & 29,65 & 12,24 & 58,11 \\
2 & 0,10 & 30,26 & 15,60 & 54,04 \\
3 & 0,81 & 29,80 & 17,54 & 51,85 \\
4 & 2,44 & 29,37 & 18,40 & 49,79 \\
5 & 2,63 & 30,65 & 17,95 & 48,78 \\
6 & 2,62 & 30,27 & 18,64 & 48,48 \\
7 & 2,59 & 29,91 & 18,97 & 48,53 \\
8 & 2,56 & 27,91 & 21,04 & 48,50 \\
9 & 3,34 & 25,65 & 21,14 & 49,88 \\
10 & 3,68 & 25,43 & 23,05 & 47,84 \\
\hline
\end{tabular}

Fonte: Dados da pesquisa com base nos resultados econométricos.

Figura 3. Resposta da quantidade a um choque na renda

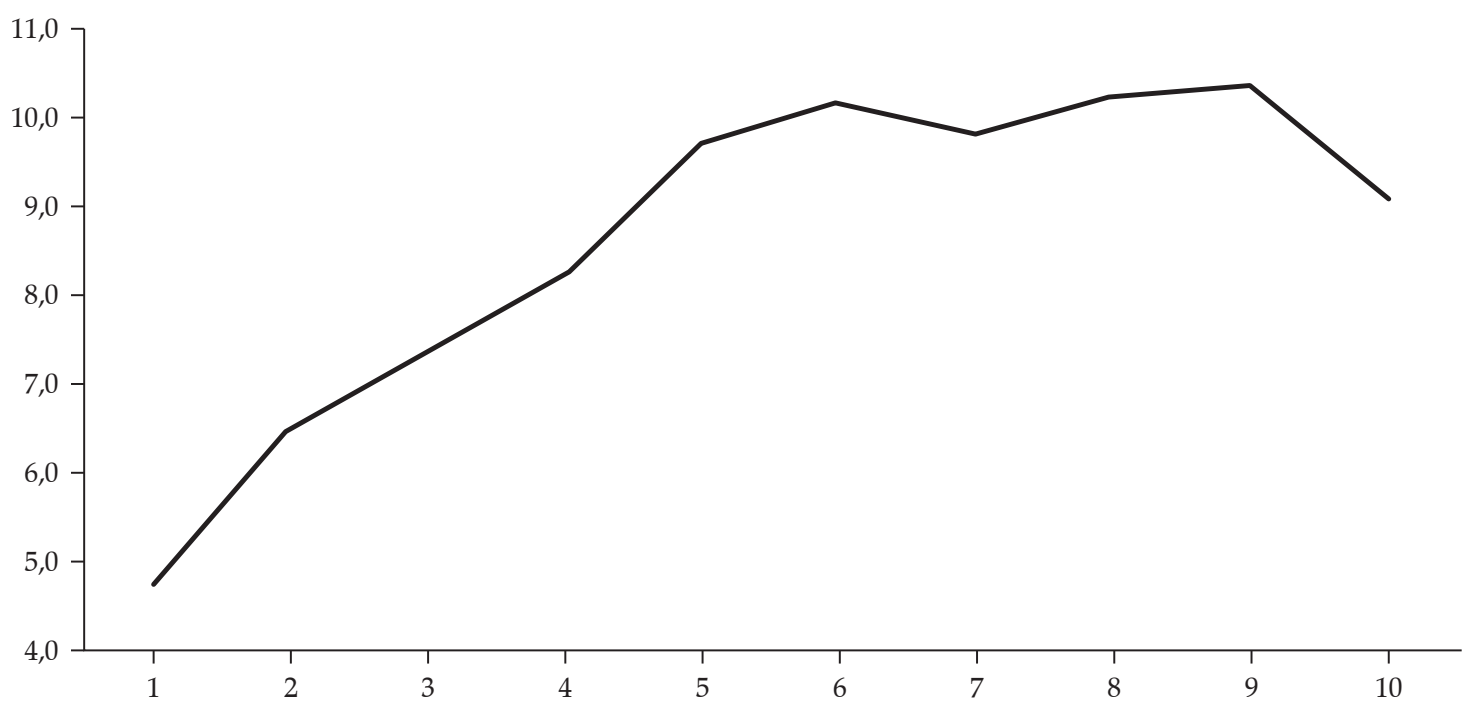

Fonte: Dados da pesquisa. 
Figura 4. Resposta da quantidade a um choque na taxa de câmbio

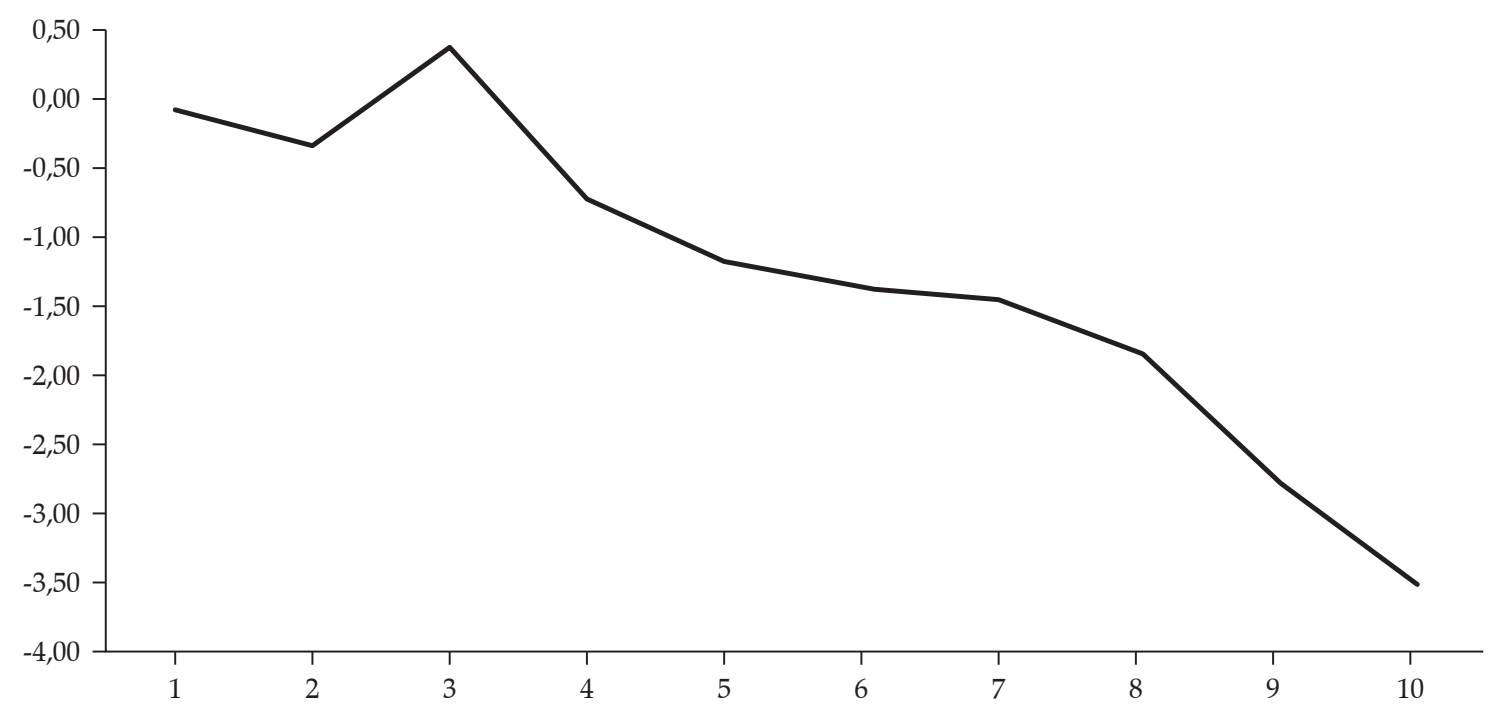

Fonte: Dados da pesquisa.

Figura 5. Resposta da quantidade a um choque no preço de importação

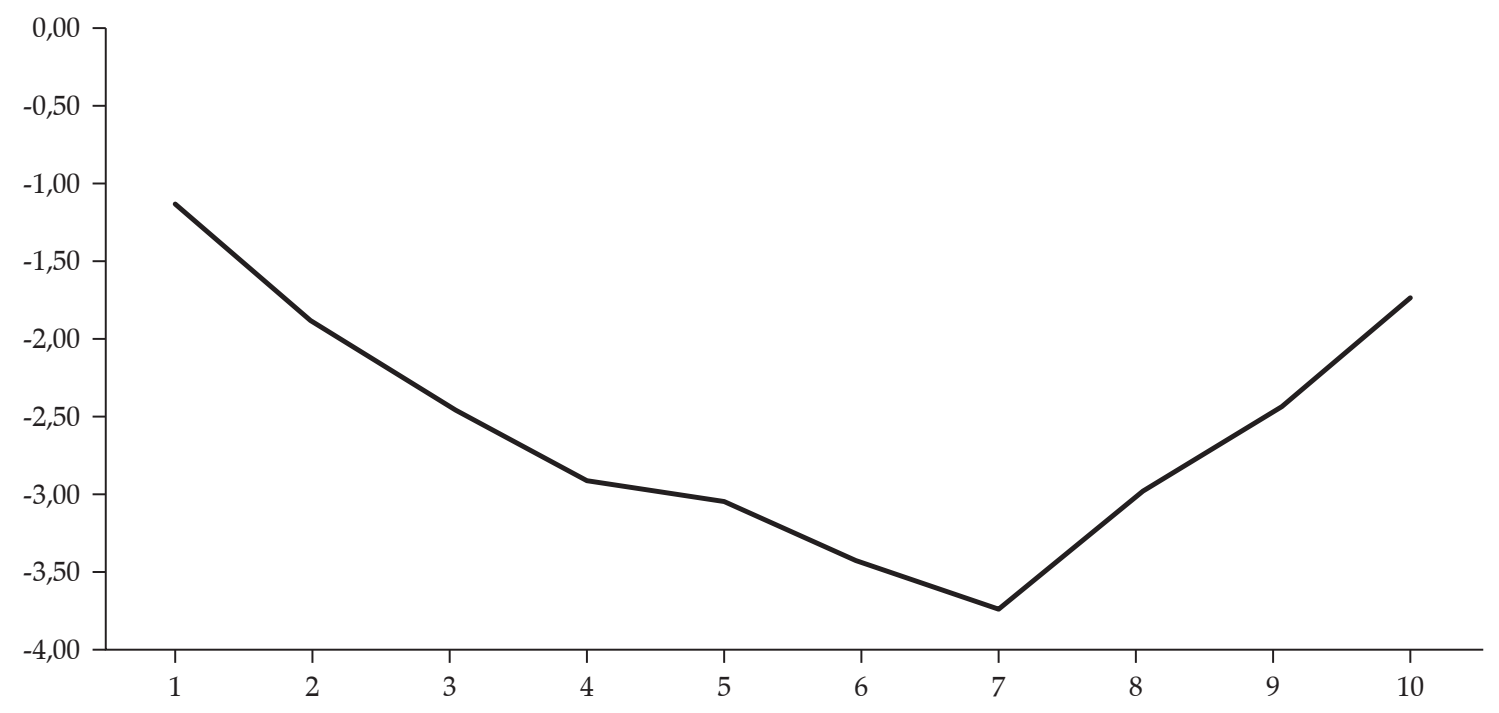

Fonte: Dados da pesquisa.

Os resultados mostram que um choque sobre a renda tem impacto positivo na importação de vinhos, como esperado. Um choque sobre a renda tem impacto ao final de dez períodos de aproximadamente nove vezes na quantidade importada de vinho. A taxa de câmbio impacta negativamente a quantidade importada, o que também era esperado. Um choque na taxa de câmbio tem impacto negativo mais de três vezes maior na quantidade ao final de 10 períodos. Os preços de importação tiveram impacto menor na quantidade de vinhos importados. Um choque sobre os preços tem um impacto relativo de uma vez e meia sobre a quantidade importada. 


\section{Considerações finais}

Como pode ser visto nos resultados do modelo AIDS, variações no preço do vinho parecem ter menos impacto nas quantidades consumidas do que entre bebidas mais populares como a cerveja. Mudanças na renda, por outro lado, aparentam ter impacto sobre o consumo de vinho maior do que o que ocorre com outras bebidas alcoólicas. Quando se considera a demanda não compensada por vinho, observa-se uma relação de complementaridade entre cerveja e vinho. $\mathrm{O}$ mesmo não se observa com outras bebidas.

Com relação ao modelo VAR estrutural, os fatores mais relevantes para explicar a variância da quantidade importada foram os preços e a renda, sendo que o câmbio apresentou menor poder explicativo, embora grande parte da variância da quantidade de vinhos importados (48\%) não esteja relacionada a estas variáveis. Assim, o modelo sugere que é possível haver outros fatores determinantes do lado da demanda. Um fato que chama a atenção é que a importação brasileira de vinho tem crescido nas últimas décadas a taxas mais elevadas do que o consumo. Para explicar esse comportamento, três razões podem ser apontadas. Em primeiro lugar, este fato pode ter ocorrido devido a uma queda nos preços dos vinhos importados devido, em parte por maior competitividade internacional na produção. Em segundo lugar, também é possível que, de fato, tenha havido mudança nas preferências de consumo dos brasileiros, que estariam mais propensos a consumir vinhos de qualidade, ao invés de consumir volume maior ou comprar a preços baixos. Nesse caso, com os investimentos em qualidade realizados pelas vinícolas locais, deve-se notar uma recuperação dos concorrentes nacionais em relação aos vinhos importados nos próximos anos. Finalmente, este maior consumo também parece estar relacionado ao aumento de renda em termos reais, motivado pela estabilização dos preços a partir de 1994 e pelo crescimento da classe média pós 2002.

Por fim, cabem algumas considerações sobre a análise feita e o futuro do mercado brasileiro de vinho. Um dos maiores limitantes encontrados para a realização da pesquisa foi a falta de dados oficiais, quase inexistentes, relativos à produção e ao consumo de vinho no País. O uso da Indicação Geográfica e Denominação de Origem do Mapa abre uma grande oportunidade para analisar a diferenciação dos produtos nacionais; no entanto, ele foi só regulamentado em 2013, um período muito recente para avaliar seu impacto.

Os diferentes padrões de qualidade do vinho não foram considerados no modelo VAR e nem pelo modelo AIDS, o que poderia ser um componente importante para entender melhor $\mathrm{o}$ mercado. Embora o modelo VAR estrutural tenha apontado uma baixa relação entre a taxa de câmbio e as quantidades de vinho importadas, uma desvalorização futura do Real poderá ter efeito negativo nas quantidades importadas de vinho. Ademais, a quantidade crescente de vinhos importados, principalmente provenientes do Chile e Argentina, que entram no mercado nacional com qualidade e preços competitivos, além do investimento em qualidade pelas vinícolas nacionais têm melhorado o conhecimento dos consumidores para melhor avaliar as relações custo-benefício. Essas são apenas algumas das hipóteses levantadas a serem investigadas por estudos futuros.

Em conclusão, espera-se que esse estudo abra novas oportunidades de pesquisa, principalmente aquelas que façam uso de pesquisa qualitativas por serem fundamentais para investigar as vantagens comparativas e limitações de cada região produtora, e também o potencial de consumo das regiões consumidoras do País.

\section{Referências}

ALVES, D., MENEZES, T. e BEZERRA, F. Estimação do sistema de demanda censurada para o Brasil: Utilizando dados de pseudopainel. In: SILVEIRA, F. G. et al. (Ed.). Gasto e consumo das famílias brasileiras contemporâneas, Vol. 2, p. 485-514. IPEA, 2007.

BUSE, A. Evaluating the Linearized Almost Ideal Demand System. American Journal of Agricultural Economics, v. 76, n. 4, p. 781-793, 1994. 
CAMPOS, A. C. e BRIGATTE, H. Demanda de importação de vinho no Brasil no período 1995-2007. In: XLIV Congresso Brasileiro de Economia e Sociologia Rural, Rio Branco, 2008.

CAPITELLO, R., AGNOLI, L. e BEGALLI, D. Chinese import demand for wine: evidence from econometric estimations. Journal of Wine Research, v. 26, n. 2, p. 115135, 2015.

CEMBALO, L., CARACCIOLO, F. e POMARICI, E. Drinking cheaply: the demand for basic wine in Italy. Australian Journal of Agricultural and Resource Economics, v. 58, n. 3, p. 374-391, 2014.

COELHO, A. B. e AGUIAR, D. R. D. O modelo quadratic almost ideal demand system (quaids): uma aplicação para o brasil. In: SILVEIRA, F. G. et al. (Ed.). Gasto e consumo das famílias brasileiras contemporâneas, Vol. 2, p. 485-514. IPEA, 2007.

CORSEUIL, C. H. e FOGUEL, M. N. Uma Sugestão de Deflatores para Rendas Obtidas a Partir de Algumas Pesquisas Domiciliares do IBGE. Texto para Discussão, n. 897. Rio de Janeiro: Instituto de Pesquisa Econômica Aplicada, 2002. Disponível em: <http://www.ipea. gov.br/portal/images/stories/PDFs/TDs/td_0897.pdf $>$. Acesso em: 26 set. 2013.

DEATON, A. e MUELlBAUER, J. An Almost Ideal Demand System. The American Economic Review, v. 70, n. 3, p. 312-326, 1980.

ELLIOTT, G., ROTHENBERG, T. J. e STOCK, J. H. Efficient tests for an autoregressive unit root. Econometrica, v. 64, n. 4, p. 813-836, 1996.

GALLET, C. A. The demand for alcohol: a metaanalysis of elasticities. Australian Journal of Agricultural and Resource Economics, v. 51, n. 2, p. 121-135, 2007.

GLASS, R. F. e CASTRO, A. M. G. As indicações geográficas como estratégia mercadológica para vinhos. Embrapa Informação Tecnológica: Embrapa-Secretaria de Gestão Estratégica, 2009. Disponível em: < http:// www.alice.cnptia.embrapa.br/bitstream/doc/512617/1/ Texto35160909.pdf>. Acesso em: 19 jun. 2015.

GUERRA, C. C. et al. Conhecendo o essencial sobre uvas e vinhos. Documentos Embrapa, 2005. 70 p. Disponível em: < http://www.agencia.cnptia.embrapa. br/Repositorio/Doc48_000fr0xs4b002wyiv80084arlty 8ck45.pdf>. Acesso em: 26 set. 2013.

IBGE - Instituto Brasileiro de Geografia e Estatística. Pesquisa de Orçamentos Familiares 2002-2003: primeiros resultados. Rio de Janeiro: IBGE, 2004, 276p.
. Pesquisa de Orçamentos Familiares 2008-2009: Despesas, Rendimentos e Condições de Vida. Rio de Janeiro: IBGE, 2010, 222p.

JOHANSEN, S. Statistical analysis of cointegration vectors. Journal of economic dynamics and control, v. 12, n. 2, p. 231-254, 1988.

MEDINA-ALBALADEJO, F. J., MARTÍNEZ-CARRIÓN, J. M. e RAMON-MUÑOZ, J. M. El mercado mundial de vino y la competitividad de los países del Hemisferio Sur, 1961-2010. América Latina en la historia económica, v. 21, n. 2 , p. $40-83,2014$.

MELLO, L. R. Vitivinicultura brasileira: Panorama 2011. Comunicado Técnico 115. Embrapa, 2012. Disponível em: <www.cnpuv.embrapa.br/publica/comunicado/ cot115.pdf $>$ Acesso em: 26 set. 2013.

MENEZES, T., AZZONI, C. R. e SILVEIRA, F. G. Demand elasticities for food products in Brazil: a two-stage budgeting system. Applied Economics, v. 40, p. 2557-2572, 2008.

MENG, Y. et al. Estimation of own and cross price elasticities of alcohol demand in the UK-A pseudopanel approach using the Living Costs and Food Survey 2001-2009. Journal of health economics, v. 34, p. 96-103, 2014.

MOSCHINI, G. The semiflexible almost ideal demand system. European Economic Review, v. 42, p. 349-364, 1998.

MUHAMMAD, A. et al. The evolution of foreign wine demand in China. Australian Journal of Agricultural and Resource Economics, v. 58, n. 3, p. 392-408, 2014.

NIEROP, M. J. R. M. The evolution of the Brazilian wine industry. Master Thesis. Universit Utrecht, 2011. Disponível em: <http://igitur-archive.library.uu.nl/ student-theses/2011-0322-200513/UUindex.html >. Acesso em: 26 set. 2013.

OSTERWALD-LENUM, M. A Note with Quantiles of the Asymptotic Distribution of the Maximum Likelihood Cointegration Rank Test Statistics. Oxford bulletin of economics and statistics, v. 54, n. 3, p. 461-472, 1992.

PROTAS, J. F. S., CAMARGO, U. A. e MELO, L. M. R. A vitivinicultura brasileira: realidade $\mathrm{e}$ perspectivas. Embrapa - Uva e Vinho, 2003. Disponível em: <http://www.cnpuv.embrapa.br/publica/artigos/ vitivinicultura/> . Acesso em: 26 set. 2013.

ROESE, M. O mundo do vinho de cabeça para baixo: as transformações no mercado internacional do vinho e o novo empresariado vinícola. Revista de sociologia e política, n. 31, p. 71-83, 2008. Disponível em: < http:// 
www.scielo.br/pdf/rsocp/v16n31/v16n31a07.pdf > . Acesso em: 5 out. 2013.

SATO, G. S. e ANGELO, J. A. As exportações brasileiras de vinhosederivados:iníciode processodeinternacionalização. X SEMEAD - Seminários em Administração FEA-USP, 2007. Disponível em: <http://www.ead.fea.usp.br/ semead/10semead/sistema/resultado/trabalhosPDF/563. pdf > . Acesso em: 26 set. 2013.

SATO, G. S. e LENCE, R. A queda da salvaguarda e as cotas no varejo para os vinhos brasileiros. Análises e Indicadores do Agronegócio, v. 7, n. 12, dez. 2012. Disponível em: <ftp://ftp.sp.gov.br/ftpiea/AIA/AIA-682012.pdf>. Acesso em: 26 set. 2013.

SHONKWILLER, J. e YEN, S. Two Step estimation of a censored system of equations. American Journal of Agricultural Economics, v. 81, n. 4, p. 972-982, 1999.
SILVA, M. M. C. e COELHO, A. B. Demanda por frutas e hortaliças no Brasil: uma análise da influência dos hábitos de vida, localização e composição domiciliar. Pesquisa e Planejamento Econômico, v. 44, n. 3, 2014.

SYROVATKA, P., CHLADKOVA, H. e ZUFAN, P. Wine consumption in the Czech Republic and the prices of alcohol. Agricultural Economics (Zemeedeelská Ekonomika), v. 60, n. 2, p. 89-98, 2014.

TERUCHKIN, S. U. As estratégias empresariais para os vinhos finos no Brasil e no Uruguai: uma análise comparada. Tese de Doutorado. Universidade Federal do Rio Grande do Sul, 2003. Disponível em: <http://hdl.handle.net/10183/4066> Acesso em: 26 set. 2013.

$\mathrm{XU}$, P. et al. Willingness to pay for red wines in China. Journal of Wine Research, v. 25, n. 4, p. 265-280, 2014. 
/* Resultados do modelo AIDS.

A equação que foi excluída durante a estimação foi o gasto com cerveja e seus parâmetros foram resgatados com base nas restrições do modelo**/

The SAS System

15:35 Friday, June 11, 2015

The SYSLIN Procedure

Iterative Seemingly Unrelated Regression Estimation

Model B

Dependent Variable shareoutras

Parameter Estimates

\begin{tabular}{|c|c|c|c|c|c|}
\hline Variable & $\mathrm{DF}$ & $\begin{array}{l}\text { Parameter } \\
\text { Estimate }\end{array}$ & $\begin{array}{l}\text { Standard } \\
\text { Error }\end{array}$ & t Value & $\operatorname{Pr}>|t|$ \\
\hline Intercept & 1 & 0.610378 & 0.069594 & 18.77 & $<.0001$ \\
\hline Ln_cerveja & 1 & -0.07544 & 0.013847 & -5.45 & $<.0001$ \\
\hline Ln_outras & 1 & 0.078472 & 0.013339 & 5.88 & $<.0001$ \\
\hline Ln_vinho & 1 & -0.00304 & 0.009498 & -0.32 & 0.7497 \\
\hline Ln_dispenp & 1 & -0.06702 & 0.010543 & -6.36 & $<.0001$ \\
\hline region1 & 1 & -0.04012 & 0.024266 & -1.65 & 0.1004 \\
\hline region2 & 1 & 0.015382 & 0.023705 & 0.65 & 0.5174 \\
\hline region3 & 1 & -0.02513 & 0.035022 & -0.72 & 0.4741 \\
\hline ano_2003 & 1 & -0.08525 & 0.022052 & -3.87 & 0.0002 \\
\hline ano_2009 & 1 & -0.05069 & 0.022673 & -2.24 & 0.0268 \\
\hline
\end{tabular}

Model C

Dependent Variable sharevinho

Parameter Estimates

\begin{tabular}{|c|c|c|c|c|c|}
\hline Variable & $\mathrm{DF}$ & $\begin{array}{l}\text { Parameter } \\
\text { Estimate }\end{array}$ & $\begin{array}{l}\text { Standard } \\
\text { Error }\end{array}$ & t Value & $\operatorname{Pr}>\mid \mathrm{t}$ \\
\hline Intercept & 1 & 0.318618 & 0.067704 & 4.71 & $<.0001$ \\
\hline Ln_cerveja & 1 & -0.03249 & 0.013353 & -2.43 & 0.0162 \\
\hline Ln_outras & 1 & -0.00304 & 0.009498 & -0.32 & 0.7497 \\
\hline Ln_vinho & 1 & 0.035522 & 0.012672 & 2.80 & 0.0057 \\
\hline Ln_dispenp & 1 & -0.02415 & 0.010162 & -2.38 & 0.0187 \\
\hline region1 & 1 & -0.04607 & 0.023665 & -1.95 & 0.0534 \\
\hline region2 & 1 & -0.06582 & 0.022910 & -2.87 & 0.0047 \\
\hline region 3 & 1 & 0.004766 & 0.034264 & 0.14 & 0.8896 \\
\hline ano_2003 & 1 & 0.009733 & 0.021670 & 0.45 & 0.6540 \\
\hline ano_2009 & 1 & 0.035914 & 0.022280 & 1.61 & 0.1091 \\
\hline
\end{tabular}

Region1 = São Paulo, Rio de Janeiro e Belo Horizonte

Region2 $=$ Belém, Fortaleza, Salvador e Recife.

Region3 = DF e Goiânia

Region 4 = Curitiba e Porto Alegre

ELASTICIDADES DE CONSUMO DE FAMILIAS URBANAS - POFS 2003 E 2009 --- TODOS OS ESTADOS DO BRASIL ${ }^{13}$

13. Os resultados das regressões estão à disposição para consulta com os autores do artigo. 
Tabela 1A. Matriz de elasticidade marshalliana

\begin{tabular}{lccc}
\hline \multicolumn{1}{c}{ Produto } & Cerveja & Outras bebidas alcoólicas & Vinho \\
\hline Cerveja & -0.949 & 0.122 & 0.104 \\
Outras bebidas & 0.155 & -0.186 & 0.163 \\
Vinho & -0.080 & 0.154 & -0.678 \\
\hline
\end{tabular}

Fonte: Dados da pesquisa com base nos resultados econométricos.

Tabela 2A. Elasticidade-renda

\begin{tabular}{lc}
\hline \multicolumn{1}{c}{ Produto } & Elasticidade-renda \\
\hline Cerveja & 0.87 \\
Outras bebidas alcoólicas & 0.66 \\
Vinho & 0.79 \\
\hline
\end{tabular}

Fonte: Dados da pesquisa com base nos resultados econométricos.

Tabela 3A. Matriz de elasticidades Hicksianas

\begin{tabular}{lccc}
\hline \multicolumn{1}{c}{ Produto } & Cerveja & Outras bebidas alcóolicas & Vinho \\
\hline Cerveja & -0.338 & 0.255 & 0.234 \\
Outras bebidas & 0.623 & -0.285 & 0.263 \\
Vinho & 0.603 & 0.267 & -0.566 \\
\hline
\end{tabular}

Fonte: Dados da pesquisa com base nos resultados econométricos. 
